Accepted for review 16 December 2013 to the Journal of Community and Applied Social Psychology

\title{
BEYOND ETHICS TO MORALITY: CHOICES AND RELATIONSHIPS IN BICULTURAL RESEARCH SETTINGS
}

\author{
JANE FURNESS, LINDA WAIMARIE NIKORA, DARRIN HODGETTS, NEVILLE ROBERTSON \\ Maori and Psychology Research Unit, University of Waikato, Hamilton, New Zealand
}

\begin{abstract}
Knowledge of ourselves as cultural beings, of the values and beliefs of those with whom we work, and of the history of relations among those in our work settings are essential for community and applied social psychologists. In New Zealand, research by non-Maori involving Maori has often mirrored the harmful colonising practices of the nation's wider history. In response, several frameworks have been developed setting out conditions and guidelines in which non-Maori might conduct research in Maori settings responsibly and usefully. Nevertheless, views differ on the ways, and extent to which, nonMaori might be involved. Most guidelines do not provide answers to ethical nuances that may arise. This article discusses the experiences of a non-Maori community psychologist engaging in research with Maori participants in a bicultural, but predominantly Maori, school-based community education setting. Insight is provided into how kaupapa Maori approaches were applied in research that was valuable to the community.
\end{abstract}

Key words: Indigenous methodologies; Maori; literacy; whanau; family

In 1642, Dutch explorer Abel Tasman led an expedition of "discovery" that partially mapped and revealed the islands which would later become known as New Zealand. After a bloody encounter with Maori in Golden Bay, he left without ever going ashore. Following in Tasman's wake, in 1769 and again in 1777, Captain James Cook of Britain led a scientific voyage to witness the Transit of Venus and to explore, document and collect resources that might benefit the motherland. Among the crew sailing with Cook were naturalists Joseph Banks and Daniel Solander. They made journals and collected specimens that were later deposited in the Royal Gardens at Kew. Also on board was artist Sydney Parkinson who created many beautiful sketches and water colours producing a window through which to view not just the natural environment but its people and artefacts. Many of these artefacts were taken and are now stored at the British Museum.

If we fast forward to this century and reflect on these voyages with a critical eye, we might construct Abel Tasman's activity as a research scoping exercise, where researchers go forth and collect knowledge about a context, people and place with an intention of some future activity. Of note was his experience in Golden Bay serving to warn others of the local inhabitant's displeasure and resistance. Cook's activities can be viewed as scientifically systematic and deliberate and mostly qualitative although not exclusively so. Journal entries made by crew members reveal methods such as 'walk-along' interviews, observations, specimen collection and description and auto-ethnographic reflection - all very modern data gathering tools! But, like Tasman's experience, Cook too encountered resistance, the result being the deaths of six Maori in what is now known as Poverty Bay. Taken by themselves, these voyages did result in fantastic scientific discoveries, yet these achievements are crushed beneath the insidious agenda and competition amongst European nations to expand their empires to exploit new lands, resources and peoples, a fact of which both Tasman and Cook were well aware and had seen its consequences.

There are some very salient lessons for today's researchers in this early encounter history of New Zealand. However, it was not until the 1950s and 60s, when the urbanisation of Maori people was at its height, that a social justice consciousness began to be articulated amongst social science researchers in New Zealand. Here, psychologists like Ernest Beaglehole, Ivan Sutherland, James and Jane Ritchie, and their respective students featured prominently (Nikora, 2007; Ritchie, 1992). Perhaps because 
culture and social justice were a huge part of their consciousness, these scholars engaged meaningfully with the research communities in which their work was embedded. James Ritchie's mantra of 'no action without research' and 'no research without action' articulated what is referred to now as transformative research, research that makes a positive and permanent difference to people's lives and circumstances.

Indigenous peoples all over the globe have been subjected to havoc wrought by outsiders upon their lands, seas, communities and cultures. Research and science must be named as tools of colonial expansion alongside, for example, genocide, mass immigration, minoritization and assimilation. In this post-colonial era, as we come to terms with the challenges of decolonisation, researchers too are being asked to decolonise their minds, hearts and practices. This challenge is more than a question of ethical practice; it is about making this world a better place for generations to come. It means extending beyond our very narrow and limited training as community and applied social psychologists to find ways to positively transform people's lives, rather than persisting in taking and colonising their knowledge and experience of often painful and ongoing circumstances. Until that challenge is realised, there will continue to be the enduring need for critical papers that scour research practice for colonial biases, cultural blindness, ethnocentrism, deep researcher insight and honesty and, more importantly, for strategies to overcome these pitfalls.

In this paper, we seek to elaborate some key ethical practices for conducting research with Maori to complement the work already in circulation by Maori researchers and theorists which we briefly review below. By critically reflecting on the experiences gained by the first author in her evaluative study of a family-focused adult literacy programme centred on a children's programme called $\mathrm{Hei}$ Awhiawhi Tamariki ki te Pukapuka (HPP) we are able to describe specific strategies helpful to informing the conceptualisation and ethical practice of research with Maori. While our focus is on working and engaging with Maori, the issues that arise have relevance for research with indigenous peoples more generally.

\section{FAMILY-FOCUSED ADULT LITERACY EDUCATION}

The New Zealand government has engaged in substantial infrastructure development of adult literacy education (cf., Ministry of Education, 2004). At the same time newly-emerging family-focused approaches have been popular among adult literacy learners and educators and some government officials (Benseman \& Sutton, 2005; Furness, 2012; May, Hill \& Donaghy, 2004). Even so, the dominant Eurocentric views held by government on literacy and its purposes continue to obstruct the inclusion of other viewpoints on how the sector, including family literacy, might be developed. Little is known publicly about different ways family literacy programmes could be structured and what potential participants might value. The default neoliberal model is skills-based, economy-focused and inflexibly structured, posing a risk that policy and funding will be narrowly, perhaps inappropriately and ineffectually prescribed. The research study upon which this paper is based sought to open a discussion space for different viewpoints, to expose the limits of existing policy and practice, and to highlight invisible or marginalised perspectives.

A concern for social justice was critical to the choice of research methodology and methods, and to the theoretical frameworks which shaped the study. The notion of, and quest for, wellbeing for all people was paramount. Wellbeing, as conceived in the study, involves interrelated experiences of physical, social-emotional, psychological, spiritual and material processes (Bornstein, Davidson, Keyes, \& Moore, 2003). It goes beyond meeting basic needs and is connected to what people value in life (Durie, 1998, Nelson \& Prilleltensky, 2005; Rochford, 2004). A concern for wellbeing, thus defined, necessitated a critical-interpretive social constructionist approach to the entire study requiring broad and inclusive conceptualisations of the elements of family-focused literacy programmes - 'family', 'literacy', 'family literacy' and 'family literacy programmes' - all of which are contested by governments, theorists and practitioners internationally.

While literacy is broadly agreed to encompass the means by which people communicate and make sense of the world, its specific forms, the purposes they serve and their relative importance are disputed. In many European nations the traditional and still dominant view of literacy is a singular one: literacy is a set of skills 'residing in people's heads'. They are skills in the 'essay-text' literacy of the dominant societal institutions, often in the English language, high levels of which are believed essential to 
economic participation and development. The alternative 'New Literacies' perspective holds that there are many literacies (many languages and communication patterns within them), many modes (or 'texts') (including image, gaze, movement) and they are often combined. In this broad view, skills are involved but literacy is primarily a social activity (Gee, 2008), its value residing in the social and relational contexts of its use rather than in any inherent qualities in literacy itself (Scribner \& Cole, 1981). For Maori, literacy is a multiple construct. It includes English and te reo Maori; oral and linguistic traditions, performance and text; and reading other 'texts' such as tribally significant landscapes, objects and their locations (Hohepa \& McNaughton, 2002; Maori Adult Literacy Educators Working Party, 2001).

Meanings of 'family', 'family literacy' and 'family literacy programmes' used in the study also differed from the dominant meanings of these concepts. Rather than being an autonomous, usually nuclear unit, 'family' in the study included a wider set of related people as well as unrelated people who had family-like relationships. 'Family literacy' was the literacy practices that occur naturally within families in their daily communal lives. 'Family literacy programmes' aim to enhance the literacy abilities of family members individually or together. Critiquing traditional ideas, these conceptualisations enabled inclusion of differing cultural realities and perspectives, provided a broad and holistic framework for analysis and drove the participatory research methods.

\section{The HPP-based Whanau Literacy Programme}

The literacy programme of interest in this article was located in a small rural community of about 400 residents. Most residents were members of the area's tribe (iwi), belonging to one or more of 12 local traditional gathering places (marae). When the research began, the bilingual school in which the programme was based had 130 Year 1-8 students of whom 98 percent were Maori. Like the principal and staff of the school, two of the three women participants in the programme were from the area. The participants each had two school-aged children. One lived with her parents and grandfather; the other lived on her marae, as did her mother. The remaining participant was married to a local person whose extended family lived nearby. Her child attended the Kohanga Reo (Maori-medium preschool). Participants, their whanau and the school frequently took part in local iwi-based activities. The school focused strongly on student, whanau and community wellbeing, emphasising the importance of whanau, relationships and life-long learning in its internal, whanau and community communications and activities.

The HPP-based programme focused on oral language development for children in Year 1 and 2 of school who were below their chronological age in oral language development and reading and on the adults who assisted them. The programme is a high quality, cohesive, relationship-based individualised approach to developing children's oral language (Atvars, Pinfold, \& Stock, 1999). While learning and using HPP the adults were encouraged to reflect on their own skills, interests and goals and to apply their learning in their personal and whanau contexts. Offered in the school in both Maori and English languages, the focus of the study was the English language-based version.

\section{RESEARCH EXPERIENCES AND ETHICAL DECISION-MAKING PROCESSES}

In this section we describe responses to ethical, moral and social justice issues identified through a process of critially reflexive research practice. We consider four domains of action and experience, narrated using the first author's voice as this reflects the work she completed as part of her PhD research and ownership of her experience. The co-authors have played an active part in interrogating the first author's reflections, insights and articulation of experience that in turn have realised the insights collectively reached in this paper.

Shifting 'voices', I am a fourth-generation New Zealander of Scottish and English descent; a member of the culture-defining Pakeha majority. I am a mother and family member, and community psychologist and educationist. I am proud of my heritage and the struggles and successes of my ancestors. Even so, I am not blind to the acts of history that have privileged me and contributed tomany of the social advantages I have and continue to enjoy. I feel no guilt about being Pakeha. However, I do feel a real urgency and comitment to advocating for a just society where all peoples fairly and equitably 
enjoy the rewards and benefits of New Zealand citizenship: no more urgent is the need to achieve social justice for Maori New Zealanders. My passion for literacy reflects my own activist agenda to alleviate oppression and parallels that vision held by educator and philosopher, Paulo Friere (1970). This is a moral analysis and reflects my own personal conscience and energised how I wanted to engage with research and Maori communities and my literacy-focused study. Related is my own personal and professional development and my active seeking to decolonise heart, mind and action, a deeply personal process.

Below, the wisdom available within the academic literature about conducting research with Maori is considered. This wisdom guided decisions about how to enter the research setting and how to build collaborative relationships with participants. This is followed by a discussion of my self-awareness and the need to remain present and responsive to research participants. The section concludes with review of how researchers care for participant information beyond secure storage and the preservation of anonymity. We believe that the issues discussed here are helpful for research not only with indigenous peoples, but with people generally.

\section{Conducting research with Maori - current wisdom}

Good researchers find out as much as they can about a research topic and read widely in the field. Better researchers come to an appreciation of the research context and the people with whom they intend to engage. A review of the existing literature concerning engagement and research with Maori beyond the research topic of interest is often overlooked or rejected as unrelated thus further perpetuating colonial and ignorant research practice. There is no shortage of information to which researchers and community psychologists who seek social justice can refer to better understand engagement and research with Maori. For more than a century, beginning with Apirana Ngata and Peter Buck (Ngata, Buck, \& Sorrenson, 1987), Maori academics have repeatedly described the foundations and methodologies involved in indigenous knowledge and 'knowing' (Smith, 1999). As Maori have gained voice in the academy, they have set out when, how and by whom research involving them or their interests may be conducted. This has been explicitly described in terms of ethical practice (cf., Te Awekotuku, 1991). Recently, Hudson, Milne, Russell and Smith (2010) developed Te Ara Tika, a framework to guide researchers and ethics committee members in the work that they do. While researchers may assert their adherence to Maori ethical value positions, rarely do Pakeha researchers articulate in any significant depth how they specifically configured their research to achieve such standards. Admirable recent exceptions are found in the work by Came (2013), a Pakeha researcher who described her work against the Te Ara Tika framework, and that by Barnes (2013) who described the engagement of four Pakeha researchers in kaupapa Maori educational relationships. Both of these works have relevance for psychologists working in community and other applied ways with indigenous peoples and suggest closer scrutiny of the ethical codes that guide research practice for such practitioners.

The Code of Ethics for Psychologists Working in Aotearoa/New Zealand (New Zealand Psychological Society, 2002) (the Code of Ethics) locates practice ethics within a set of values derived from te Tiriti o Waitangi (the Treaty of Waitangi) (Te Tiriti). Signed between the British Crown and Maori tribes in 1840, Te Tiriti was understood by the British to cede them sovereignty, allow the Crown to purchase land from those willing to sell, and provide a mandate for a settler government (kawanatanga). Maori understood it to protect their rangatiratanga or self-determination, selfgovernance and resources and make for a peaceful and ordered society. While debate continues about the intent and contemporary implications of Te Tiriti, there is a reasonably broad consensus about the principles which underlie it. These are commonly thought to include working in partnership, taking protective action to preserve the interests of Maori and seeking their active and informed participation in decision-making.

The architects of the Code of Ethics have cleverly reflected the persistent colonial tension encapsulated by Te Tiriti by referencing the Rangatiratanga - Kawanatanga Dynamic elaborated by Nikora (2001). This dynamic holds that the exercise of kawanatanga must be balanced against the exercise of rangatiratanga and vice versa. This implies more than an incidental relationship. It is one where the futures of both Maori and Pakeha are interdependent and entwined with that of the other. In reality, perfect relationships are rare. They have to be worked at and worked out. In so doing, such 
relationships have real potential for positive and healthy growth and wellbeing. Applied in the Code of Ethics, the dynamic suggests that psychologists must build relationships with Maori research communities, stakeholders and participants that are equally cognisant of rangatiratanga and kawanatanga responsibilities. As Nairn (2007) explains, rangitiratanga encompasses caring for the needs of people (manakitanga), protecting and caring for all creation (kaitiakitanga) and creating and sustaining relationships (whanaungatanga). The professional status of psychology situates the practitioner in a position of power. Psychologists must be conscious of their kawanatanga responsibilities: that is "to ensure the spaces we control are safe for Maori and other non-culturedefining peoples" (Nairn, 2007, p. 28). To this end, the Code of Ethics implores psychologists to demonstrate respect for the dignity of persons and peoples, responsible caring, integrity in relationships, and a concern for social justice and responsibility to society.

While the Code of Ethics is often the first and sometimes only instrument that is consulted for guidance to avoid unethical practice with Maori, there are now many more informative sources to which responsible researchers can look. Foremost is the seminal and much-quoted work by Linda Tuhiwai Smith (1999). Her deconstruction of research 'on' rather than 'with' indigenous people resulted in her proposing five critical and helpful positions for ethical research in Maori settings. For Smith, ethical research requires respect for 1) Maori values, beliefs and worldview (tikanga) and how these are promoted, protected and developed (kawa); 2) the interconnectedness of all things through genealogy (whakapapa); 3) the embeddedness of worldviews, social practices and histories in te reo Maori (the Maori language); 4) governance and control in matters which affect them (rangatiratanga); 5) family (whanau) (who provide the support structure for the research). Bishop (1999) adds a further position, that is, 6) the establishment of relationships within the research whanau (whakawhanaungatanga). Smith elaborates that practices which uphold these positions include a respect for people (aroha ki tangata); presenting oneself face-to-face (kanohi ki te kanohi); looking, listening and finding a place to speak (titiro, whakarongo... korero); sharing and hosting people, reciprocity (manaakitanga); being cautious (kia tupato), and not faulting your knowledge (kaua e mahaki).

In addition to the above wisdom, is that proffered by Graham Smith (1992) who describes four models for how Pakeha might work with Maori. In the tiaki (mentoring) model the Pakeha researcher enlists an authoritative Maori person to guide and support the research so that it is conducted appropriately. The whangai (adoption) model involves researchers immersing themselves in the daily lives of their participants so that a close relationship develops which might extend beyond the life of the research. The power-sharing model requires the researcher to seek engagement of the Maori community in the research in meaningful ways. In the empowering outcomes model, Pakeha researchers respond to questions Maori want answered and which lead to beneficial outcomes for them. Other models are the bicultural model in which Maori and Pakeha researchers work together on a project (Powick, 2002) and the accountability model in which structures are created to ensure that the rangatiratanga of Maori is upheld through the involvement of 'monitors, experts and authorities' (Huygens, 1999, p. 18).

This growing literature (and similar international literature, cf., Chilisa, 2012; Purdie, Dudgeon, \& Walker, 2010) is vital reading for Pakeha researchers wishing to engage Maori in research and work in Maori communities. It is not difficult to find and makes the plea of ignorance untenable. Practicing ethically, however, requires more of the researcher than following a set of guidelines in a processional way. The ethical nuances of research will serve to trip those who approach research like this. To this end, researchers must develop an ethical sophistication. I hope that the strategies I describe below will be informative.

\section{Early critical reflection and decision-making}

There were many issues to consider prior to entering the field and engaging specifically with Maori programme providers, learners and families. Three of these were the grounds on which I believed it was important to involve Maori; whether I had sufficient knowledge, cultural awareness and sensitivity to work respectfully and with integrity with Maori; and what accountability to Maori might mean for my research practice. 
I proceeded by adopting what Narayan (1988) called methodological humility and caution. I talked with Pakeha researchers who had often worked with Maori and who were respected in the Maori world, about the appropriateness of the research and my involvement. I believed I had sufficient knowledge, awareness and sensitivity to be able to 'feel my way through' but that I would need to be vigilant, constantly critically reflective and to actively seek, and be open to accepting, guidance. This was an iterative process where I revisited decisions, looked to learn more from the literature and critically reflected on conversations seeking deeper understanding and meaning.

I needed to reconcile the tension I felt between wanting the work to be valued and adopted by government, and government's tendency to regard random controlled trials as the 'gold standard' in research, an approach inappropriate for this study. I chose a qualitative case study approach to reveal the perspectives of participants in the context of the realities of their lives. I hoped to enhance the likelihood of the research being recognised as robust and useful by thoroughly explaining the basis for the trustworthiness of the findings. It was important to nurture my relationships with decision-makers and people who could influence policy and ensure that they understood the rationale for the approaches adopted. I realised that in the longer-term, the social change strategy would be a political one and I needed allies with influence.

\section{Establishing relationships}

I began by contacting the Maori trust board which held the contract to deliver the HPP programme. Planning to phone soon after they would have received the information, I wrote introducing myself and outlining the research purpose and proposed processes. I received a letter before I had phoned, referring me to the project director - the person directly involved in delivering the contract. I already knew the project director through our working together on another literacy project. I phoned her and we discussed the research. On her advice I sent her written information. Then, with this in hand, she discussed the idea with the school principal and the programme participants, finding them supportive. She was the only one among them who knew me, and I was the sole Pakeha. The trust the principal had in the project director, and the trust the participants had in the project director and the principal, were very important in their early consideration of the research.

The next important step was meeting first hand those who would be involved. The project director and I organised a lunch for potential participants where we discussed the project and the part we wanted the women to play. It was important that I knew 'myself' as participants were interested in situating my family, knowing who they were, where I was from, and how I was connected to the people and the context of the research. In this regard, my having a working relationship with the project director created a place in their minds, for me, as a Pakeha, next to her in their context. The process of establishing these initial relationships was characterised by step-wise entry through the whanau of the project so that they could establish whether I was trustworthy, the project worthwhile, and their participation meaningful and safe.

The project director and the school principal saw value in the proposed research: it was an opportunity to help the programme develop and potentially increase the availability of such programmes. The women were keen to document their experiences of the programme and the benefits they felt could be enjoyed by others. While the study was favourably received, I was concerned to allow the school principal, project director and participants the time needed for them to discuss the project and me as a researcher. It was important that I did not rush them or appear to be in a rush. They all had to come to the research table of their own volition and with their own vision and sense of rangatiratanga that would endure beyond the life of the research.

The initial information gathering process in which each of the women mapped their social network served as a way for them to get to know me better and to settle on their decision to participate. I discussed with them, in recorded interviews, their roles and tasks in the context of their networks, identifying the literacy aspects. This exercise provided a reference point for discussing changes in their lives over the course of the programme and beyond. The participants sat together whilst constructing their own network map. I sat nearby, facilitating the process and sharing my own map as a general guide. This was a relaxed time, strengthening our relationships and cementing a way of working together that involved sharing, conversation and reciprocity. This reflects the need to be face-to-face, be accountable, 
spend time getting to know people and being willing to adapt to their needs rather than simply pushing one's research agenda. The participants were also aware that they could withdraw from the project at any time but this was never taken for granted by me and I revisited their willingness to continue, formally and informally throughout the study.

In the early stages, I identified who might provide guidance to the research about appropriate processes and use of protocols. The school principal and project director were the elders (kaumatua) in the setting aware of cultural, community and school 'rules, restrictions, behaviours and practices'. As such they became the primary caretakers of the research. I checked my procedures with them, as well as with the women in the programme, and also garnered their views on who else needed to be a part of or kept informed about the project. As well as the trust board, the local iwi education authority knew about the research through the project director who met with them regularly. At her request I passed the report of my initial findings on to the authority. On the caretakers advice I updated the trust board and iwi authority on progress as I began the final analysis and later sent them the final draft of the introduction, findings/discussion and conclusions chapters for their comment if they wished. As I had from the outset, I offered to meet with them if they wanted to hear more about the research or had questions or concerns. The caretakers of the research along with the programme participants constituted who I was primarily accountable to. However it was also appropriate to be transparent and open about the research with the wider whanau who might have an interest.

\section{Discursiveness and reflexivity}

The women were interviewed early in their participation in the programme for baseline data and after approximately 6 months and 18 months for information about changes over time. The interviews, which could take up to two hours, were conversational in style. Lead questions and sub-questions/prompts developed for each topic were used as a guide and checklist rather than being followed rigidly. I sometimes shared my own stories and often the participants told stories unrelated to the research which were not analysed but which formed part of the relational fabric of the researcher-participant interaction. I chose this approach realising that reciprocity and trust between researcher and participant were essential to understanding the family literacy 'reality'. The conversational style, the repeat interviews and the amount of time together were important and allowed for relationships to develop and understanding to be explored and checked in processes of 'spiral discourse' (co-constructing of meaning over time through repeat conversations) and 'dialogic reflexivity' (reflection on meaning through conversation) (Bishop \& Glynn, 1999).

Along with the discursive and reflexive processes described above, my analysis was conducted within the broad and inclusive theoretical frameworks in which the project was embedded. It also involved extensive checks with participants (Mutch, 2005; Reissman, 2008). My role was to understand the participants' perspectives as much as possible but at the same time to respect and understand the limits in my understanding that may occur so as to avoid distorted claims. This required closeness to the participants' lives as the information was gathered and analysed, along with awareness of how insider/outsider dynamics might operate. For example, the women did not specifically talk to me about spirituality when I raised it in relation to wellbeing, and on reflection and further study, have concluded that their response was probably more about being asked a 'strange' question of a world to which I was an outsider. The work by Nikora, Te Awekotuku and Tamanui (2013) discusses Maori spirituality as a space between people, places and objects and is more about relationality and balance than about spirit per se suggesting that I should have pursued a different line of conversation.

I gave participants their verbatim interview transcripts inviting them to delete, add or change anything they had said so that they continued to have control over the information they contributed. I found I needed to reassure some participants that seemingly 'untidy' speech was 'normal' in conversation (and mine was like that too). Other such processes included giving participants drafts of the initial analysis, papers, presentations and report chapters before they were finalised or publicly available so that changes could be made if necessary. It was important to ensure that everyone was satisfied that the representation was fair. In hindsight I think the raw transcripts and the volume of material I gave them was probably overwhelming and would suggest less time-consuming methods for checking meaning and interpretation next time. I received detailed feedback from the project director 
and I know that some reading was done by the school principal and the women and they were satisfied with what they read.

\section{Looking after people - looking after knowledge}

Looking after people and the information they shared was important and needed to move beyond the secure storage of raw data and preserving anonymity. Looking after people required me to be organised so that I did not waste their time, being prepared before meetings with them so that I was clear in my interactions and requests, and respecting their choice in level of involvement (for example, the extent to which they read and gave feedback on transcripts and drafts). Taking breaks in interviews, providing morning or afternoon teas or lunch, and ensuring timing of visits were suitable and re-scheduling if need be were all important for the women's wellbeing. They were already busy in their families and community and I did not wish to intrude or create stress. I deeply appreciated their contributions and wanted to look after any needs they had to make it as easy as possible for them to participate.

It was important that findings were given to the community in ways that suited them, a matter discussed with the caretakers of the research and the participants (the research whanau). Two summaries, one briefer than the other, were provided to the school principal and the school's Board of Trustees, the project director and the programme participants, written in an accessible style (in comparison to a large thesis) and therefore more likely to be useful to the school and of interest to the women. I also provided a hard copy of the thesis and the web link to the principal and Board of Trustees and the project director. I made it clear that I was available to help in the utilisation of the knowledge gained if requested as part of my ongoing obligation to the community. It is a way I can reciprocate for the time and effort they have contributed to the research and to my personal and professional learning and development. Moreover, the research should be shared more widely and used. This paper and three others have been published to date, two others are in progress, and several workshops and presentations have been given to literacy educators. The school principal, project director and the programme participants are always invited to be involved but have been content to leave the dissemination to me or to me and the project director. I have co-presented with the project director and we are planning a paper for publication. It is also important to recognise when those who have been involved in the research are ready for you to move on! I gave a small koha to each participant - book vouchers they could use for themselves or their families - and to the school towards resources to support their literacy work. These were small ways I could show my appreciation for the time they gave to the research, for sharing parts of their lives with me and for their trust in me to look after them and their families through the process and to do something that, though it may not benefit them directly (although they found it personally interesting, enlightenng and rewarding), would contribute to a wider conversation which might come to benefit others in theirs or other communities in the future.

There is no denying that I feel an attachment and obligation to this research community and the genuine relationships I developed and I know I can pick up again with them from where we left off. My present post-study focus now rests with my political and sector allies and how the findings of the research can be used to leverage change and to improve the availability of appropriate and meaningful literacy programmes for Maori and their communities.

\section{CONCLUSION}

In this paper we situated the ethicality of research within a broader historical, cultural and social context. We began by considering early European voyagers into our waters and highlighted the perils of engaging communities of which little is known. We pointed out that many of the research techniques used by them were not too different to those used by researchers today. However, what is different is the extent to which we are aware of harmful research practice, and, therefore, the necessity for an advanced ethical consciousness. Yet a cursory scan of journals in social, community and cross-cultural psychology reveals that the majority of authors fail to explicitly articulate and analyse the ethicality of their work, instead relying on an endorsement from their institutional ethics committee. For indigenous 
communities, Maori included, this is not good enough and we echo the call by Bishop (1996) for researchers not to abrogate their responsibilities.

We described the readily-available and growing canon of literature to guide the Pakeha researcher, and this might also generalise to other non-indigenous researchers. Certainly indigenous peoples have been consistently vocal about research in their communities and have contributed to the literature on research ethics. Failure to engage with this literature and adopt a critically reflexive response to research with indigenous people is to act irresponsibly and unethically. The attention, time and energy invested by a researcher in understanding a research topic should at least parallel that put into understanding and engaging the research community and participants, and developing a methodology appropriate to and for them.

We note too, that with increased pressure from government and universities academics will find themselves increasingly engaged with diverse communities. The principles set out in this article are crucial to ensure ethical research practice across cultures and diversity. Finally, we observe that there will always be challenges; we cannot develop guidelines for every nuance which may occur in research so each person must develop their own morality which guides them at a deep fundamental level.

\section{ACKNOWLEDGEMENTS}

The first author thanks the Faculty of Arts and Social Sciences, University of Waikato for its financial and academic support, through the Postdoctoral Writing Stipendiary Award, for the writing of this article. I would also like to thank Diana Coben, National Centre of Literacy and Numeracy for Adults, University of Waikato for her support of the Award application. The study on which this article is based was supported by a Tertiary Education Commission Bright Future Doctoral Scholarship. We also thank Peter Isaacs, Literacy Aotearoa for his assistance.

\section{REFERENCES}

Atvars, K. R., Stock, A. \& Pinfold, C. (1999). Hei Awhiawhi Tamariki ki te Panui Pukapuka (a storybook reading tutoring programme) Rotorua Tauranga Contract Manual 200-2001. Rotorua, NZ: Ministry of Education.

Barnes, A. (2013).What can Pakeha learn from engaging in kaupapa Maori educational research? Wellington, NZ: NZCER.

Benseman, J. \& Sutton, A. (2005). Summative evaluation of the Manukau Family Literacy Project (2004). Auckland: NZ: University of Auckland and Auckland Uniservices.

Bishop, R. (1996). Collaborative research stories: Whakawhanaungatanga. Palmerston North, NZ: Dunmore.

Bishop, R., \& Glynn, T. (1999). Culture counts: Changing power relations in education. Palmerston North, NZ: Dunmore.

Bornstein, M., Davidson, L., Keyes, C., \& Moore, K. A. (2003). Well-being: Positive development across the life course. Mahwah, NJ: Lawrence Erlbaum.

Braun, V., \& Clarke, V. (2006). Using thematic analysis in psychology. Qualitative Research in Psychology, 3, 77-101.

Came, H. A. (2013). Doing research in Aotearoa: a Pākehā exemplar of applying Te Ara Tika ethical framework. Kotuitui: New Zealand Journal of Social Sciences Online, 1-10. doi: 10.1080/1177083X.2013.841265

Chilisa, B. (2012). Indigenous research methodologies. Thousand Oaks, Calif: SAGE Publications.

Durie, M. (1998). Whaiora: Māori health development ( $2^{\text {nd }}$ ed.). Auckland, NZ: Oxford University Press.

Freire, P. (1970). Pedagogy of the oppressed. New York, NY: Herder and Herder.

Furness, J. (2012). The contribution of family literacy programmes to the wellbeing of individuals, families and communities. Unpublished PhD Thesis. Hamilton, New Zealand: University of Waikato. Available at http://hdl.handle.net/10289/6457

Gee, J. P. (2008). Social linguistics and literacies: Ideology in discourses ( ${ }^{\text {rd }}$ ed.). London, UK: 
Routledge.

Hohepa, M. \& McNaughton, S. (2002 Indigenous literacies: The case of Maori literacy. In L. Makin, \& C. Jones Diaz (Eds.), Literacies in early childhood (pp. 215-232). Marrickville, New South Wales, Australia: MacLennan \& Petty.

Huygens, I. (1999). Accountability model for Pakeha practitioners. In N. Robertson (Ed.), Proceedings of the Maori and Psychology: Research and practice symposium (pp. 17-22) Hamilton, New Zealand: Maori and Psychology Research Unit, University of Waikato.

Maori Adult Literacy Working Party, (2001). Te kawai ora: Reading the world, reading the word, being the world: Report of the Maori Adult Literacy Working Party. Wellington, NZ: Te Puni Kokiri.

May, S., Hill, R., \& Donaghy, A. (2004), Review of whanau literacy projects: Final report to the Tertiary Education Commission. Hamilton, New Zealand: Wilf Malcolm Institute of Educational Research, University of Waikato.

Ministry of Education. (2004). Learning for Living: Te ako mo te ora (1). Retrieved from http://www.minedu.govt.nz

Mutch, C. (2005). Doing educational research: A practitioner's guide to getting started. Wellington, NZCER Press.

Narayan, U. (1988). Working together across difference: Some considerations on emotional and political practice. Hypatia, 3(2), 31-47.

Nairn, R. (2007). Ethical principles and cultural justive in psychological practice. In Evans, I. M. Rucklidge, J. J. \& O'Driscoll, M. (Eds.), Professional practice of psychology in Aotearoa New Zealand. Wellington, NZ: The New Zealand Psychological Society.

Nelson, G., \& Prilleltensky, I. (Eds.), (2005). Community psychology: In pursuit of liberation and well-being. New York, NY: Palgrave Macmillan.

New Zealand Psychological Society (2002). Code of Ethics for psychologists working in Aotearoa/New Zealand 2002. Wellington, NZ: New Zealand Psychological Society.

Ngata, A. T., Buck, P. H., \& Sorrenson, M. P. K. (1987). Na to hoa aroha: The correspondence, 1925-50. Auckland, NZ: Auckland University Press.

Nikora, L. W. (2001). The Rangitiratanga - Kawanatanga dynamic. Keynote address to Annual Conference of the New Zealand Psychological Society, NZ Psychological Society Bulletin, 99, pp. 29-32.

Nikora, L. W. (2007). Maori social identities in New Zealand and Hawai'i. Unpublished PhD Thesis, University of Waikato, Hamilton, New Zealand.

Nikora, L.W., Te Awekotuku, N., \& Tamanui, V. (2013). Home and the spirit in the Maori world. Paper presented at the He Manawa Whenua Indigenous Research Conference, 30 June-3 July 2013. Hamilton, New Zealand.

O'Driscoll, M. (Eds.). Professional practice of psychology in Aotearoa New Zealand. Wellington, NZ: The New Zealand Psychological Society.

Powick, K. (2002). Nga take matatika mo te mahi rangahou Maori. Maori research ethics: A literature review of the ethical issues and implications of Kaupapa Maori research and research involving Maori for researchers, supervisors and ethics committees. Hamilton, NZ: Wilf Malcolm Institute of Educational Research, University of Waikato.

Purdie, N., Dudgeon, P., Walker, R., Australia., Australian Council for Educational Research., Kulunga Research Network., \& Telethon Institute for Child Health Research. (2010). Working together: Aboriginal and Torres Strait Islander mental health and wellbeing principles and practice. Canberra: Australian Institute of Health and Welfare.

Reissman, C. K. (2008). Narrative methods for the human sciences. Los Angeles, CA: Sage.

Ritchie, J. (1992). Becoming bicultural. Wellington, NZ: Huia/Daphne Brasell Associates.

Rochford, T. (2004). Whare Tapa Wha: A Maori model of a unified theory of health. The Journal of Primary Prevention, 25(1), 41-57

Scribner, S. \& Cole, M. (1981). The psychology of literacy. Cambridge, MA: Harvard University Press.

Smith, L. T. (1999). Decolonising methodologies: Research and indigenous peoples. London, UK: Zed Books.

Smith, G. (1992). Research issues related to Maori education. In Research Unit for Maori Education 
(Ed.), The issue of research and Maori. Auckland, NZ: University of Auckland.

Te Awekotuku, N. (1991). He tikanga whakaaro: Research ethics in the Maori community: a discussion paper. Wellington, NZ: Ministry of Maori Affairs.

Udy, K., Walker, M., \& Pole. N., May, S., Chamberlain, G., \& Sturrock, F. (1996). Adult Literacy in New Zealand: Results from the International Adult Literacy Survey. Wellington, NZ: Ministry of Education. 